\title{
Germinação de sementes de Myrsine coriacea (Primulaceae) submetidas a diferentes tratamentos para superação da dormência
}

\author{
Renata Rodrigues Lucas', Gustavo Crizel Gomes², Ernestino de Souza Guarino ${ }^{3}$, Thales Castilhos \\ de Freitas ${ }^{4}$, Silvana Wachholz do Amaral ${ }^{5}$, Letícia Penno de Sousa ${ }^{3}$, Adalberto Koiti Miura ${ }^{3}$ \& \\ Caroline Jácome Costa ${ }^{3}$
}

\begin{abstract}
'Universidade Federal de Santa Catarina, Programa de Pós-graduação em Recursos Genéticos Vegetais, Centro de Ciências Agrárias, Rodovia Admar Gonzaga, 1346. Bairro Itacorubi, CEP 88.034-001, Florianópolis, SC, Brasil. renata.lucas85@gmail.com 2Universidade Federal de Pelotas, Programa de Pós-graduação em Sistemas de Produção Agrícola Familiar, Campus Capão do Leão, Faculdade de Agronomia Eliseu Maciel, Departamento de Fitotecnia, CEP 96010-900, Pelotas, RS, Brasil. crizelgomes@gmail.com ${ }^{3}$ Embrapa Clima Temperado, Rodovia BR-392, Km 78, $9^{\circ}$ Distrito, Monte Bonito, CEP 96010-971, Pelotas, RS, Brasil. ernestino.guarino@embrapa.br, leticia.penno@embrapa.br, adalberto.miura@embrapa.br, caroline.costa@embrapa.br 4Universidade Federal de Pelotas, Campus Capão do Leão, CEP 96010-900, Pelotas, RS, Brasil. thales.castilhos@gmail.com 5 Instuto Federal de Educação, Ciência e Tecnologia Sul-Rio-Grandense, Campus Pelotas, Praça Vinte de Setembro, 455, Bairro Centro, CEP 96015-360, Pelotas, RS, Brasil. sil29wa@hotmail.com
\end{abstract}

RESUMO - Myrsine coriacea (Sw.) R. Br. ex Roem. \& Schult. é uma espécie arbórea nucleadora e alvo de intensa frugivoria, contribuindo para deposição de sementes de outras espécies. Devido suas sementes permanecerem no banco de sementes do solo, favorece a regeneração florestal após distúrbios naturais ou antrópicos. Com o objetivo de testar diferentes métodos para superação da dormência das sementes, foram analisados os seguintes tratamentos: Controle (TC), Escarificação Química (TQ), Escarificação Mecânica (TM) e Escarificação Térmica (TT). Foram avaliados os parâmetros: Percentual de Germinação (PG \%), Índice de Velocidade de Germinação (IVG) e Tempo Médio de Germinação (TMG/dias). Para todos os parâmetros, o TM foi o mais eficaz para promoção da germinação, pois elevou a porcentagem e a velocidade de germinação, observando-se maior número de sementes germinadas em menor espaço de tempo. O TQ adotado foi deletério, e por isso não é recomendado. Não houve diferença significativa entre TC e TT.

Palavras chave: escarificação, restauração ecológica, sementes florestais

ABSTRACT - Seed germination of Myrsine coriacea (Primulaceae) submitted to different dormancy breaking treatments. Myrsine coriacea (Sw.) R.Br. ex Roem. \& Schult. is a tree species with nucleation characteristics and a target to frugivorous animals, which contributes to the seed deposition to other plants. $M$. coriacea seeds remain in the soil for long periods, regenerating the forest after natural and anthropogenic disturbances. Four different methods were analysed with the aim to verify different types of breaking seed dormancy: Control (TC); Chemical Scarification (TQ); Mechanical Scarification (TM); Thermal Scarification (TT). The following parameters were evaluated, percentage of germination (PG) (\%), germination speed index (IVG), and mean time of germination (TMG) (days). For all the parameters, we found that TM was more efficient at promoting germination, because it increased the percentage and speed of germination, which was observed with more seeds germinating in a short period of time. Meanwhile no difference was noticed between TC and TT, and the TQ was deleterious and is not recommended to break seed dormancy.

Keywords: ecological restoration, forestry seeds, scarification

\section{INTRODUÇÃO}

Myrsine coriacea (Sw.) R.Br. ex Roem. \& Schult. (Primulaceae) é popularmente denominada de capororoquinha ou capororoca. Ocorre do México ao Uruguai (Otegui 1998) e no Brasil está presente desde a Bahia ao extremo sul do Rio Grande do Sul (Carvalho 2003), estado onde se encontra em todas as formações florestais (Sobral et al. 2006). É uma espécie pioneira, cujos frutos de dispersão zoocórica, são produzidos em abundância (Lorenzi 1992, Backes \& Irgang 2002, Carvalho 2003) e amplamente consumidos pela fauna, que se encarrega da dispersão das sementes, sendo seus principais agentes dispersores as aves (Pineschi 1990, Pizo et al. 2002, Jesus \& Monteiro Filho 2007, Basler et al.2009, Begnini \& Castellani 2013, Kaminski 2013), mas também mamíferos (Kuhlmann 1975, Oliveira \& Leme 2013).

Espécies com as características de atração de fauna frugívora são essenciais nos processos de regeneração florestal (Jordano et al. 2006), sendo atribuídas a elas a qualidade de nucleadoras (Reis et al. 1999). Ao atraírem animais e servirem de poleiros naturais, ajudam a incrementar a chuva de sementes e a regeneração florestal, pois por defecação ou regurgitação, novas sementes são depositadas sob suas copas, contribuindo com o estabelecimento de outras espécies. Begnini \& Castellani (2013) avaliaram a chuva de sementes sob indivíduos de $M$. coriacea, constatando sua influência positiva na deposição 
de propágulos de novas espécies ao ambiente, sobretudo aqueles de dispersão zoocórica. Reis \& Kageyama (2003) enfatizam a importância destas relações interespecíficas nos processos de restauração ecológica.

Sementes de espécies do gênero Myrsine são classificadas quanto ao comportamento em armazenamento como ortodoxas (Carvalho 2003, Carvalho et al. 2006, Mori et al. 2012). A ortodoxia significa que as sementes se mantêm viáveis mesmo após dessecação, havendo espécies que germinam mesmo com $5 \%$ de umidade (Carvalho et al. 2006). Para o setor produtivo de sementes e mudas florestais, espécies com tal comportamento apresentam uma vantagem em relação às recalcitrantes, visto que podem ser armazenadas por longos períodos, enquanto que as recalcitrantes devem ser semeadas imediatamente após a coleta, pois perdem poder germinativo com a perda d'água (Carvalho et al. 2006).

Além do comportamento das sementes em armazenamento, o conhecimento sobre a presença (ou ausência) de dormência e métodos para sua superação, têm implicações diretas para o setor de produção de sementes e mudas, bem como para os processos de regeneração florestal natural ou induzida, como a semeadura direta. Sementes dormentes são aquelas que, mesmo viáveis, não germinam imediatamente, quando fornecidas todas as condições ambientais ideais (Fenner 1995). Esta suspensão temporária da germinação resulta da ação de mecanismos (físicos, químicos, morfológicos e/ou fisiológicos) que, aparentemente, evoluíram para aumentar as chances de regeneração de espécies submetidas a determinadas condições climáticas, não sendo ocasional, e podendo se estender de alguns dias a anos (Oliveira \& Baccarin 2001). No entanto, para a produção de mudas via sementes, a dormência passa a ser um obstáculo, por retardar a germinação, prejudicando o processo produtivo.

Baskin \& Baskin (1998) afirmam que a maioria das espécies da família Primulaceae não apresenta dormência, no entanto esta característica é reconhecida para diferentes espécies do gênero Myrsine, inclusive M. coriacea. Para Fowler \& Bianchetti (2000), a dormência nesta espécie é de natureza morfológica e/ou fisiológica, embora Carvalho (2003) e Mori et al. (2012), afirmem que a dormência seja de origem física. Joly \& Fellipe (1979) e Pereira \& Jacobi (2014) atribuem a dormência em sementes de M. guianensis e M. parvifolia, respectivamente, à impermeabilidade do endocarpo pétreo (física). Burrows (1994, 1996) demonstrou que sementes de M. australis têm sua germinação inibida quando expostas à luz, provavelmente devido ao desenvolvimento de dormência secundária, aquela adquirida após a dispersão (Sert et al. 2009, Souza 2009). A diversidade de tipos de dormência descritos para este gênero demonstra a singularidade no seu comportamento pré-germinativo.

Atuando em conjunto, estes mecanismos (dormência e ortodoxia), constituem importantes estratégias de sobrevivência para diversas espécies arbóreas pioneiras, que permanecem no banco de sementes dos solos florestais por longos períodos. Para o gênero Myrsine, a permanência no banco de sementes, em conjunto com sua ampla dispersão zoocórica tornam a espécie tão expressiva no início do processo de sucessão da Floresta Ombrófila Mista, que Klein (1980), ao definir nomenclatura com base na composição florística, para os estágios iniciais de regeneração secundária em regiões desta formação florestal, propôs o termo Rapanietum para capoeiras com predominância de $M$. coriacea (a espécie era denominada Rapanea ferruginea, sinônimo heterotípico).

Com a entrada em vigor da lei $\mathrm{n}^{\circ} 12.651$, de 25 de maio de 2012 (Lei de Proteção da Vegetação Nativa ou apenas Novo Código Florestal Brasileiro) (Brasil 2012), esperase que a demanda por sementes e mudas para restauração florestal aumente em todo o país nos próximos anos (Silva et al. 2015), sendo fundamental o levantamento de informações sobre o comportamento germinativo de espécies florestais nativas, para gerar avanços em processos de reprodução e restauração ecológica. Muitos aspectos para a germinação de espécies arbóreas nativas são ainda pouco conhecidos (Zamith \& Scarano 2004). Neste contexto a baixa taxa germinativa e o longo tempo para germinação são entraves à produção de mudas de $M$. coriacea. Com isso, o objetivo deste trabalho foi avaliar diferentes métodos para a superação da dormência de sementes de $M$. coriacea.

\section{MATERIAL E MÉTODOS}

\section{Obtenção e beneficiamento dos frutos}

Os frutos de $M$. coriacea foram coletados de três matrizes distantes, pelo menos, 25 metros entre si, na sede da Embrapa Clima Temperado ( $31^{\circ} 40^{\prime} 38^{\prime \prime}$ e e 52 $26^{\prime} 14^{\prime \prime} \mathrm{W}$ ), no município de Pelotas, Rio Grande do Sul, localizada na região fisiográfica da Encosta do Sudeste, tem como tipologia vegetal a Floresta Estacional Semidecidual (Teixeira et al. 1986). O clima enquadra-se, conforme o sistema de classificação climática de Koeppen, no tipo 'Cfa' (subtropical úmido) (Wrege et al. 2011, Alvares et al. 2013). Os frutos foram selecionados de acordo com o estágio de maturação, indicado pela coloração roxoescuro a preto (Lorenzi 1992, Carvalho 2003). Quanto ao beneficiamento, foi realizada manualmente a despolpa dos frutos, sendo em seguida as sementes submetidas à lavagem com hipoclorito de sódio $(\mathrm{NaClO}$ - teor de cloro ativo entre 2 e $2,5 \%$ ), acrescido de cinco gotas de detergente, durante três minutos, e em seguida enxaguadas com água destilada por três vezes.

\section{Teste de germinação e delineamento experimental}

Foi empregado delineamento experimental inteiramente casualizado com 12 repetições, cada uma contendo 25 sementes, distribuídas em caixas gerbox sobre duas folhas de papel mata-borrão umedecidas com duas vezes e meia a sua massa seca (Brasil 2009, Brasil 2013). Foram avaliados quatro métodos para superação da dormência das sementes: Controle (TC) - sementes não submetidas a nenhum tratamento para superação de dormência; Escarificação 
Química (TQ) - sementes escarificadas quimicamente, permanecendo imersas em ácido sulfúrico concentrado $98 \%$, durante quatro minutos, e em seguida lavadas com água destilada por três vezes antes da semeadura. Por precaução, para que o TQ não fosse deletério às sementes, optou-se por aplicar tempo de imersão em ácido sulfúrico inferior ao utilizado por Pereira \& Jacobi (2014) para $M$. parvifolia (a partir de 10 minutos) e ao recomendado por Carvalho (2003) para M. coriacea; Escarificação Mecânica (TM) - sementes escarificadas manualmente sobre lixa de madeira (n.80), para remoção parcial do tegumento; Escarificação Térmica (TT) - imersão em água destilada à temperatura de $20^{\circ} \mathrm{C}$ durante 12 horas, seguida de imersão em água à temperatura de $30^{\circ} \mathrm{C}$ por mais 12 horas, conforme indicado por Brasil (2009) e Mori et al. (2012). Após os procedimentos para superação da dormência, as sementes foram mantidas em câmara de germinação à temperatura de $25^{\circ} \mathrm{C}$ até o término das avaliações, as quais foram realizadas semanalmente, durante 98 dias. Foram consideradas germinadas todas as sementes que emitiram a raiz primária ou parte do embrião (critério botânico ou morfológico sensu Borghetti \& Ferreira 2004).

\section{Variáveis analisadas e análise estatística}

Além da germinação ( $\% \mathrm{G})$ e com o objetivo de avaliar a cinética do processo de germinação, foram calculados o Índice de Velocidade de Germinação: $I V G=\mathrm{G}_{1} / \mathrm{N}_{1}+\mathrm{G}_{2} / \mathrm{N}_{2}+$ $\ldots+\mathrm{G}_{\mathrm{i}} / \mathrm{N}_{\mathrm{j}}$; onde: $\mathrm{G}_{\mathrm{i}}=$ número de sementes germinadas e $\mathrm{N}_{\mathrm{j}}=$ número de dias após a semeadura (Maguire 1962, Borghetti \& Ferreira 2004) e o Tempo Médio de Germinação: TMG $=\sum \mathrm{n}_{\mathrm{i}} * \mathrm{t}_{\mathrm{i}} / \sum \mathrm{n}_{\mathrm{i}}$; onde: $\mathrm{n}_{\mathrm{i}}=$ número de sementes germinadas entre o intervalo de avaliação das sementes $\mathrm{t}_{\mathrm{i}}$ (Borghetti $\&$ Ferreira 2004).

Os dados foram analisados utilizando-se a plataforma estatística R (versão 3.2.5; R Core Team 2016), com nível de significância $(\alpha) \leq 0,05$. Foi avaliada previamente a normalidade dos resíduos (teste de Shapiro-Wilk; Zar 1999) e a homogeneidade das variâncias (teste de Barlett's; Zar 1999). Os parâmetros \% $\mathrm{G}$ e IVG não apresentaram normalidade $(\mathrm{W}=0.789 ; p<0.0001$ [germinação] $\mathrm{e} \mathrm{W}=$ $0.838 ; p=0.0001[\mathrm{IVG}])$ e variância homogênea $\left(\mathrm{K}^{2}=\right.$ 196,56; g.1. = 9; $p<0.0001$ [germinação] e $\mathrm{K}^{2}=8.801$; g.l. $=2 ; p=0.0122[\mathrm{IVG}])$, mesmo depois de transformadas $\left(\mathrm{x}+0,5, \log _{10}(\mathrm{x}+0,5), \sqrt{\mathrm{x}}+0,5, \operatorname{arcoseno}(\sqrt{\mathrm{x}})\right)$. Para estes casos, optou-se por utilizar o teste de Kruskal-Wallis (Santana \& Ranal 2004) com o teste post-hoc de Nemenyi para medianas (Pohlert 2016). Para a variável TMG, a qual apresentou normalidade ( $\mathrm{W}=0.969 ; p=0.410) \mathrm{e}$ variância homogênea $\left(\mathrm{K}^{2}=1.201\right.$; g.l. $\left.=2 ; p=0.549\right)$, optou-se por utilizar Análise de Variância (ANOVA) para um fator com teste post-hoc de Tukey para múltiplos contrastes (Santana \& Ranal 2004). As medianas dos parâmetros \%G e IVG são apresentados seguidos dos seus respectivos intervalos inter-quartis $\left(\mathrm{IQR}=\mathrm{Q}_{1}-\mathrm{Q}_{3}\right.$; onde $\mathrm{Q}_{1}=1^{\circ}$ quartil e $\mathrm{Q}_{3}=3^{\circ}$ quartil), enquanto a média do parâmetro TMG é apresentada seguida do seu respectivo desvio-padrão.

\section{RESULTADOS E DISCUSSÃO}

Sementes de $M$. coriacea submetidas à escarificação mecânica apresentaram maior germinação (mediana $=80 \%$, $\mathrm{IQR}=18 \%$, Fig. 1), IVG (mediana $=1,632 ; \mathrm{IQR}=0,362$, Fig. 2) e menor TMG (média $=60,619 \pm$ desvio-padrão $=44,523-$ Tab. 1). A diferença entre este tratamento $\mathrm{e}$ os demais foi estatisticamente significativa, para todos os parâmetros avaliados (teste de Kruskall-Wallis: $X^{2}=40,074$; g.l. $=3 ; p<0,001$, Tabs. 1, 2; Figs. 2, 3), não existindo diferença estatística significativa entre os tratamentos controle (TC) e escarificação térmica (TT). As Regras para Análise de Sementes (Brasil 2009) prescrevem temperaturas alternadas como método de superação de dormência para um grande número de espécies e, de acordo com o levantamento realizado por Mori et al. (2012), o tratamento térmico

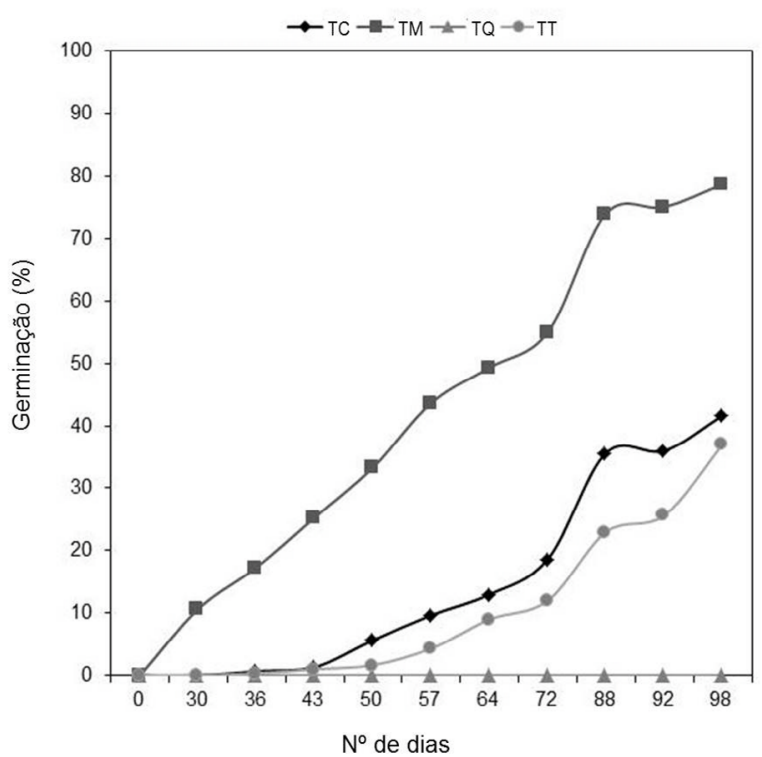

Fig. 1. Curva de germinação de sementes de $M$. coriacea submetidas a diferentes tratamentos para superação da dormência. TC $=$ Tratamento controle; $\mathrm{TM}=$ Tratamento com escarificação mecânica; $\mathrm{TQ}=$ Tratamento escarificação química e TT = Tratamento com escarificação térmica.

Tabela 1. Média e desvio-padrão para o Tempo Médio de Germinação (TMG) de sementes de $M$. coriacea submetidas a diferentes tratamentos para superação da dormência. Letras diferentes indicam diferenças significativas (teste post-hoc de Tukey para múltiplos contrastes $-p<$ $0,001) . \mathrm{TC}=$ Tratamento controle, $\mathrm{TM}=$ Tratamento com escarificação mecânica e TT = Tratamento com escarificação térmica.

\begin{tabular}{cc}
\hline Tratamentos & Média \pm Desvio-padrão (dias) \\
\hline TM & $60,62 \pm 44,52^{\mathbf{a}}$ \\
TC & $76,76 \pm 58,67^{\mathrm{b}}$ \\
TT & $83,38 \pm 61,54^{\mathbf{c}}$ \\
\hline
\end{tabular}

Tabela 2. Análise de Variância (ANOVA) para o fator tratamento. $\mathrm{gl}=$ graus de liberdade, $\mathrm{SQ}=$ Soma de quadrados, $\mathrm{M}=$ Quadrados médios, $F=$ Teste de Fischer, $\mathrm{p}=$ significância do Teste de Fischer.

\begin{tabular}{cccccc}
\hline & $\mathrm{gl}$ & $\mathrm{SQ}$ & $\mathrm{M}$ & $\mathrm{F}$ & $\mathrm{p}$ \\
\hline Tratamentos & 2 & 3289 & 1644,6 & 53,56 & $<0.001^{*}$ \\
Resíduos & 33 & 1013 & 30,7 & - & - \\
\hline
\end{tabular}




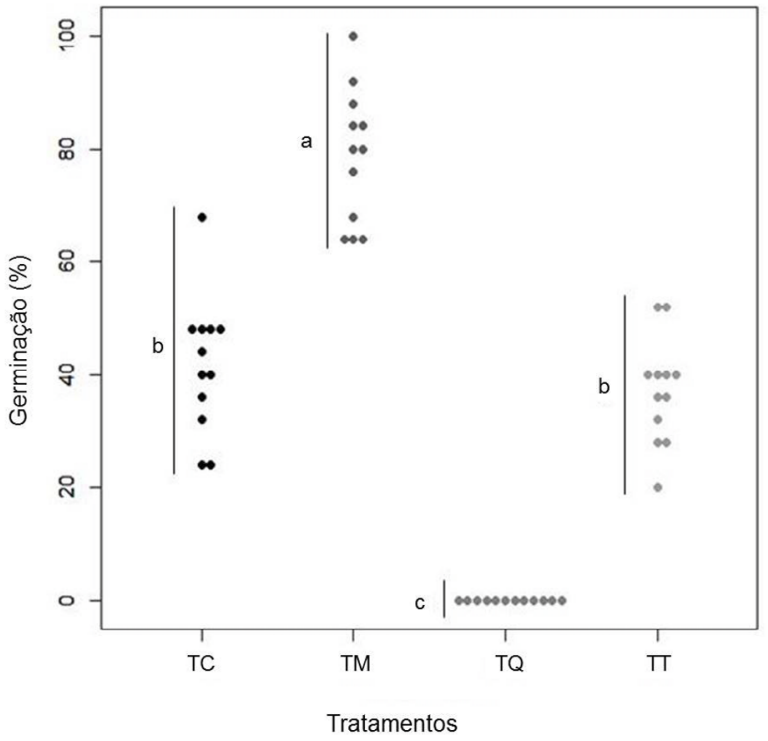

Fig. 2. Germinação (\%) para cada repetição de sementes de $M$. coriacea submetidas a diferentes tratamentos para superação da dormência. Letras diferentes indicam diferenças significativas (teste post-hoc de Nemenyi para as medianas: $-p<0,001)$. TC $=$ Tratamento controle; TM = Tratamento com escarificação mecânica; $\mathrm{TQ}=$ Tratamento escarificação química e TT = Tratamento com escarificação térmica.

utilizado neste trabalho $\left(12\right.$ horas à $20^{\circ} \mathrm{C}$ seguidos de 12 horas à $30^{\circ} \mathrm{C}$ ) seria eficaz para $M$. coriacea, no entanto este método não apresentou resultado significativo. Sementes submetidas à escarificação química não germinaram durante o intervalo de avaliação (Figs. 1,2). Devido a isto, IVG e TMG não foram calculados para este tratamento.

Em experimento onde foram avaliados diferentes métodos para superação da dormência de sementes de M. parvifolia, Pereira \& Jacobi (2014) obtiveram resultados bastante similares aos demonstrados aqui, onde a escarificação mecânica (neste caso, aberturas com bisturi na inserção do pedúnculo e na extremidade oposta) foi superior aos demais métodos avaliados, sendo que os métodos de escarificação química utilizados (imersão em $\mathrm{H}_{2} \mathrm{SO}_{4}$ concentrado por 10; 20; 30 e 40 minutos) foram também pouco promissores. No presente estudo, o período de imersão em ácido sulfúrico foi reduzido para quatro minutos, não contribuindo para a obtenção de melhores resultados, embora Carvalho (2003) recomende a imersão por cinco minutos, sem referir resultados.

É importante ressaltar que, 30 dias após a semeadura, o TM já apresentava $10 \%$ de sementes germinadas, e ao final do experimento (98 dias) apresentou aproximadamente $80 \%$. Carvalho (2003) descreve, para a mesma espécie, germinação de $73 \%$, iniciada entre 60 a 120 dias após a semeadura, para sementes submetidas a tratamentos para superação da dormência (embora o autor não especifique o tratamento), e 33\% de germinação, iniciada entre 120 e 180 dias, para sementes não submetidas a nenhum tratamento.

Os métodos para superação de dormência utilizados neste estudo vêm apresentando resultados semelhantes em pesquisas com outras espécies florestais. Em muitos

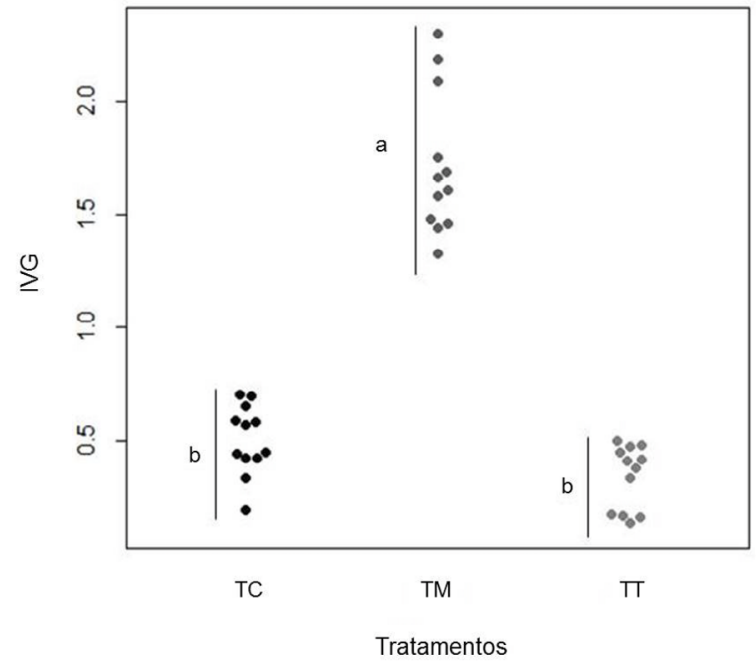

Fig. 3. Índice de Velocidade de Germinação (IVG) para cada repetição de sementes de $M$. coriacea submetidas a diferentes tratamentos para superação da dormência. Letras diferentes indicam diferenças significativas (Kruskal-Wallis: $\mathrm{X}^{2}=25,754$; g.l. $=2 ; p<0,0001$ e teste post-hoc de Nemenyi para as medianas $-p<0,001) . \mathrm{TC}=$ Tratamento controle; $\mathrm{TM}=$ Tratamento com escarificação mecânica e TT $=$ Tratamento com escarificação térmica.

casos, a escarificação mecânica também vem demonstrando respostas positivas, como para diversas espécies da família Fabaceae, entre elas Leucaena diversifolia (Schltdl.) Benth. (Bertalot \& Nakagawa 1998), Bauhinia monandra Britt. (Alves et al. 2000), Vachellia caven (Molina) Seigler \& Ebinge (Escobar et al. 2010) e Bowdichia virgilioides Kunt (Albuquerque et al. 2007). Este método também se mostrou eficiente para espécies de outras famílias botânicas, como Vitex megapotamica (Spreng.) Moldenke (Lamiaceae) (Vianna \& Koehler 2007) e Schinopsis brasiliensis Engl. (Anacardiaceae) (Alves et al. 2007).

Alguns estudos avaliaram a superação de dormência em espécies de Myrsine com outra perspectiva, comparando a germinação de sementes coletadas em plantas, com outras retiradas das fezes de aves e mamíferos, partindo do pressuposto que a passagem pelo trato digestório dos animais teria efeito de superar a dormência das sementes. Pineschi (1990) avaliou a germinação de sementes de sete espécies de Myrsine, dentre estas M. coriacea, obtendo como resultado $8,5 \%$ de sementes germinadas retiradas das fezes de aves capturadas, contra nenhuma semente germinada dentre as coletadas diretamente nas plantas. Castiglioni et al. (1995), comparando a germinação de sementes de M. parvifolia recolhidas das fezes de aves da espécie Ramphocelus bresilius L. (Emberizidae) com sementes coletadas diretamente de plantas matrizes, não obtiveram sementes germinadas para ambas as situações. Guerta et al. (2011) avaliaram a germinação de sementes de Myrsine umbellata Mart.e Myrsine lancifolia Mart. após a passagem pelo trato digestório de diferentes espécies de aves (24 espécies para M. umbellata e 12 espécies para $M$. lancifolia), comparando-as com sementes não ingeridas por aves, não encontrando diferença significativa entre os tratamentos. 
Oliveira \& Leme (2013) avaliaram a germinação de sementes de $M$. coriacea coletadas nas fezes de Didelphis albiventris Lund (Didelphidae), obtendo resultado de germinação significativamente superior para as sementes que passaram pelo trato digestório desta espécie, quando comparadas com o tratamento controle. Os autores também avaliaram a germinação de sementes escarificadas mecanicamente (tratamento idêntico ao TM aqui relatado), no qual foi obtido resultado significativamente superior ao controle, porém inferior ao tratamento de passagem da semente pelo trato digestório. Contudo, os dados obtidos para as sementes escarificadas mecanicamente por Oliveira \& Leme (2013), foram inferiores aos aqui apresentados, no entanto as sementes que passaram pelo trato digestório de $D$. albiventris, apresentaram germinação próxima ao TM do presente estudo.

A diversidade de respostas obtidas na germinação de sementes florestais submetidas a tratamentos para superação de dormência física demonstra a singularidade no comportamento de cada espécie. A escarificação mecânica de sementes florestais com dormência tegumentar ou do endocarpo pétreo, como as de M. coriacea, pode ser adaptada à realidade de viveiristas produtores de espécies florestais, com o uso de escarificadores, como os cilíndricos e revestidos com lixa, movidos a motor elétrico ou manualmente conforme já vem sendo utilizado para outras espécies como para Apuleia leiocarpa (Vogel) J.F. Macbr. (Pontes et al. 2002) e para Acacia mearnsii Willd. (Roversi et al. 2002). Para novos experimentos envolvendo a escarificação química de $M$. coriacea, recomendamse testes com períodos de imersão inferiores a quatro minutos ou diferentes concentrações de ácido sulfúrico. Para estudos futuros, recomenda-se a estratificação em areia úmida, conforme sugerido por Abdo (2015) e Mori et al. (2012).

\section{REFERÊNCIAS}

Abdo, M.T.V.N. 2015. Transferência de tecnologia: guia prático para quebra de dormência de sementes de espécies florestais nativas. Pesquisa \& Tecnologia 12(2):1-7.

Albuquerque, K.S., Guimarães, R.M., Almeida, I.F. \& Clemente, A.D.C.S. 2007. Métodos para a superação da dormência em sementes de sucupira-preta (Bowdichia virgilioides Kunth.). Ciência e Agrotecnologia 31(6):1716-1721.

Alves, A.F., Carvalho Guerra, M.E. \& Medeiros Filho, S. 2007. Superação de dormência de sementes de braúna (Schinopsis brasiliense Engl.). Revista Ciência Agronômica 38(1):74-77.

Alves, M.C.S., Medeiros-filho, S., Andrade-neto, M. \& Teófilo, E.M. 2000. Superação da dormência de sementes de Bauhinia monandra Britt. e Bauhinia ungulata L. - Caesalpinoideae. Revista Brasileira de Sementes 22(2):139-144.

Alvares, C.A., Stape, J.L., Sentelhas, P.C., Gonçalves, J.L.M. \& Sparovek, G. 2013. Köppen's climate classification map for Brazil. Meteorologische Zeitschrift 22(6):711-728.

Backes, P. \& Irgang, B. 2002. Árvores do Sul: guia de identificação e interesse ecológico. Instituto Souza Cruz, Santa Cruz do Sul. 326 p.

Baskin, C.C. \& Baskin, J.M. 1998. Seeds. Ecology, biogeography, and evolution of dormancy and germination. Academic Press, San Diego. $666 \mathrm{p}$.

Basler, A., Müller, E. \& Petry, M.V. 2009. Frugivory by birds in Myrsine coriacea (Myrsinaceae) inhabiting fragments of mixed Araucaria
Forest in the Aparados da Serra National Park, RS, Brasil. Revista Brasileira de Ornitologia 17(2):113-120.

Begnini, R.M. \& Castellani, T.T. 2013. Seed rain under the canopies of female and male Myrsine coriacea, a pioneer tree from the Brazilian Atlantic forest. Journal of Tropical Ecology 29(5):391-399.

Bertalot, M.J. \& Nakagawa, J. 1998. Superação da dormência em sementes de Leucaena diversifolia (Schlecht.) Bentham. Revista Brasileira de Sementes 20(1):39-42.

Borghetti, F. \& Ferreira, A.G. 2004. Interpretação de resultados de germinação. In Germinação: do básico ao aplicado (F. Borghetti \& A.G. Ferreira, orgs.). Armed, Porto Alegre, p. 209-222.

Brasil. Congresso Nacional. Lei de Proteção da Vegetação Nativa. Lei n ${ }^{\circ}$ 12.651 , de 25 de maio de 2012. Dispõe sobre a proteção da vegetação nativa; altera as Leis nos 6.938, de 31 de agosto de 1981, 9.393, de 19 de dezembro de 1996, e 11.428, de 22 de dezembro de 2006; revoga as Leis nos 4.771, de 15 de setembro de 1965, e 7.754, de 14 de abril de 1989, e a Medida Provisória no2.166- 67, de 24 de agosto de 2001; e dá outras providências. Diário Oficial da União, Brasília, DF, 28 mai. 2012. Disponível em <http://www.planalto. gov.br/ccivil_03/_Ato2011-2014/2012/Lei/L12651compilado.htm>. Acesso em 10. 12. 2015.

Brasil. 2009. Regras para análise de sementes. Ministério da Agricultura, Pecuária e Abastecimento, Brasília. 395 p.

Brasil. 2013. Instruções para análise de sementes de espécies florestais. Ministério da Agricultura, Pecuária e Abastecimento, Brasília. 97 p.

Burrows, C. 1994. Fruit, seeds, birds and the forests of Banks Peninsula. New Zealand Natural Sciences 21(1):87-108.

Burrows, C. 1996. Germination behaviour of seeds of the New Zealand woody species Coprosma foetidissima, Freycinetia baueriana, Hoheria angustifolia, and Myrsine australis. New Zealand Journal of Botany 34(4):499-508.

Carvalho, L.R., Silva, E.A.A. \& Davide, A.C. 2006. Classificação de sementes florestais quanto ao comportamento no armazenamento. Revista Brasileira de Sementes 28(2):15-25.

Carvalho, P.E.R. 2003. Espécies arbóreas brasileiras. Embrapa Florestas, Colombo. 1039 p.

Castiglioni, G.D.A., Cunha, L.S.T. \& Gonzaga, L.P. 1995. Ramphocelus bresilius como dispersor das sementes de plantas da restinga de Barra de Maricá, Estado do Rio de Janeiro (Passeriformes: Emberizidae). Ararajuba 3(1):94-99.

Escobar, T.A., Pedroso, V.M., Bonow, R.N. \& Schwengber, E.B. 2010. Superação de dormência e temperaturas para germinação de sementes de Acacia caven (Mol.) Mol. (Espinilho). Revista Brasileira de Sementes 32(2):124-130.

Fenner, M. 1995. Ecology of seed banks. Seed Development and Germination. Marcel Dekker, New York, p. 507-528.

Fowler, J.A.P. \& Bianchetti, A. 2000. Dormência em sementes florestais. Embrapa Florestas, Colombo. 27 p.

Guerta, R.S., Lucon, G.L., Motta-Junior. J.C., Vasconcellos, L.A.S. \& Figueiredo. R.A. 2011. Bird frugivory and seed germination of Myrsine umbellata and Myrsine lancifolia (Myrsinaceae) seeds in a cerrado fragment in southeastern Brazil. Biota Neotropica 11(4):59-65.

Jesus, S. \& Monteiro-Filho, E.L.A. 2007. Frugivoria por aves em Schinus terebinthifolius (Anacardiaceae) e Myrsine coriacea (Myrsinaceae). Revista Brasileira de Ornitologia 15(4):585-591.

Joly, C.A. \& Felippe, G.M. 1979. Dormência das sementes de Rapanea guianensis Aubl. Revista Brasileira de Botânica 2(1):1-6.

Jordano, P., Galetti, M., Pizo, M.A. \& Silva, W.R. 2006. Ligando frugivoria e dispersão de sementes à biologia da conservação. In Biologia da conservação: essências (C.F.D. Rocha, H.G. Bergallo, M. Van Sluys \& M.A.S. Alves, eds.). Rima Editora, São Paulo, p. 411-436.

Kaminski, N. 2013. Consumo de frutos por três espécies de Picidae em área de Floresta Ombrófila Mista de Santa Catarina. Biotemas 26(3):261-263.

Klein, R.M. 1980. Ecologia da Flora e Vegetação do Vale do Itajaí. Sellowia 32:164-369.

Kuhlmann, M. 1975. Adenda alimentar dos bugios. Silvicultura em São Paulo 9:57-62.

Lorenzi, H. 1992. Árvores brasileiras: manual de identificação e cultivo de plantas arbóreas nativas do Brasil. Plantarum, Nova Odessa, São Paulo. 352 p. 
Maguire, J.D. 1962. Speed of germination-aid in selection and evaluation for seedling emergence and vigor. Crop Science 2(1):176-177.

Mori, E.S., Piña-Rodrigues, F.C. \& Freitas, N.P. 2012. Sementes florestais: guia para germinação de 100 espécies nativas. Instituto Refloresta, São Paulo. 159 p.

Oliveira, A.K.M. \& Leme, F.T.F. 2013. Didelphis albiventris como indutor de germinação de Rapanea ferruginea (Myrcinaceae) em área de Cerrado, Mato Grosso do Sul, Brasil. Iheringia. Série Zoológica 103(4):361-366.

Oliveira, R.S. \& Bacarin, M.A. 2001. Banco de sementes e mecanismos de dormência em sementes de plantas daninhas. In Plantas daninhas e seu manejo (R.S. Oliveira \& J. Constantin, orgs.). Agropecuária, Guaíba, p. 261-290.

Otegui, M. 1998. Sinopsis Del gênero Myrsine L. (Myrsinaceae) em El Cono Sur de América del Sur. Candollea 53(1):133-157.

Pereira, P.E.E. \& Jacobi, U.S. 2014. Avaliação da maturidade, superação da dormência de sementes e crescimento inicial da raiz de Myrsine parvifolia A. DC.(Primulaceae). Iheringia. Série Botânica 69 (2):293-301.

Pineschi, R.B. 1990. Aves como dispersoras de sete espécies de Rapanea (Myrsinaceae) no maciço do Itatiaia, estados do Rio de Janeiro e Minas Gerais. Ararajuba 1(1):73-78.

Pizo, M.A., Silva, W.R., Galetti, M. \& Laps, R. 2002. Frugivory in cotingas of the Atlantic Forest of southeast Brazil. Ararajuba 10(2):177-185.

Pohlert, T. 2016. The Pairwise Multiple Comparison of Mean Ranks Package (PMCMR). R package. Disponível em: https://cran.r-project. org/web/packages/PMCMR/index.html

Pontes, C.A., Borges, E.E.L.B., Rita, C.G. \& Soares, C.P.B. 2002. Mobilização de reservas em sementes de Apuleia leiocarpa (Vogel) J.F. Macbr. (garapa) durante a embebição. Revista Árvore 26(5):593601.

R Core Team. 2016. R: A language and environment for statistical computing, Version 3.2.5. R Foundation for Statistical Computing. Disponível em: https://www.R-project.org/. Acesso em: 04. 07. 2016.

Reis, A. \& Kageyama, P.Y. 2003. Restauração de áreas degradadas utilizando interações interespecíficas. In Restauração ecológica de ecossistemas naturais (P.Y. Kageyama, R.E. Oliveira, L.F.D. Moraes,
V.L. Engel, \& F.B. Gandara, orgs.). Fundação de Estudos e Pesquisas Agrícolas e Florestais, Botucatu, p. 91-110.

Reis, A., Zambonin, R.M. \& Nakazono, E.M. 1999. Recuperação de áreas florestais degradadas utilizando a sucessão e as interações planta-animal. Conselho Nacional da Reserva da Biosfera da Mata Atlântica, São Paulo. 42 p.

Roversi, T., Falck, G., Mattei, V.L. \& Silveira Junior, P. 2002. Superação da dormência em sementes de acácia negra (Acacia mearnsii Willd.). Pesquisa Agropecuária Brasileira 8(2):161-163.

Santana, D.C. \& Ranal, M.A. 2004. Análise estatística. In Germinação: Do básico ao aplicado (F. Borghetti \& A.G. Ferreira, orgs.). Armed, Porto Alegre, p. 197-208.

Sert, M.A., Bonato, C.M. \& Souza, L.A. 2009. Germinação da semente. In Sementes e plântulas: germinação, estrutura e adaptação (L.A. Souza, org.). Toda Palavra, Ponta Grossa. 279 p.

Silva, A.P.M., Marques, H.R., Santos, T.V.M.N., Luciano, M.S.F. \& Sambuichi, R.H.R. 2015. Diagnóstico da Produção de Mudas Florestais Nativas no Brasil - Relatório de Pesquisa. Instituto Nacional de Pesquisa Econômica Aplicada, Brasília. 58p.

Sobral, M., Jarenkow, J.A., Brack, P., Irgang, B., Larocca, J. \& Rodrigues, R.S. 2006. Flora arbórea e arborescente do Rio Grande do Sul, Brasil. Editora Rima/Novo Ambiente, São Carlos. 362 p.

Souza, L.A. 2009. Sementes e plântulas: germinação, estrutura e adaptação. Toda Palavra, Ponta Grossa. 279 p.

Teixeira, M.B., Coura Neto, A.B., Pastore, U. \& Rangel Filho, A.L.R. 1986. Vegetação. As regiões fitoecológicas, sua natureza e seus recursos econômicos. Estudo fitogeográfico. In Levantamento de recursos naturais. Instituto Brasileiro de Geografia e Estatística 33:541-632.

Vianna, E. \& Koehler, A.B. 2007. Tratamentos simplificados para germinação de sementes de tarumã (Vitex megapotamica (Spreng.) Moldenke.). Revista Acadêmica 5(2):189-193.

Wrege, M.S., Steinmetz, S., Reisser Júnior, C. \& Almeida, I.D. 2011. Atlas climático da região sul do Brasil: estados do Paraná, Santa Catarina e Rio Grande do Sul. Embrapa Clima Temperado, Pelotas. 336 p.

Zamith, L.R. \& Scarano, F.R. 2004. Produção de mudas de espécies das Restingas do município do Rio de Janeiro, RJ, Brasil. Acta Botanica Brasilica 18(1):161-176.

Zar, J. H. 1999. Biostatistical analysis. Prentice Hall, New Jersey. 663 p. 